\title{
Research on the Operational Mechanism of The Maker Space Based on Ecosystem Theory
}

\author{
Lei Wang ${ }^{1, a}$, Wan-yi Gong ${ }^{1, b}$, Ming-dong Jiang ${ }^{1,2, c,{ }^{*}}$ \\ ${ }^{1}$ School of Business Administration, Hohai University, Changzhou 213022, China \\ ${ }^{2}$ Study and Research Group of The thought of socialism with Chinese characteristics in the new er \\ a ,Hohai University, Changzhou 213022, China \\ a15061119532@163.com, b453732627@qq.com, chhujmd@126.com \\ ${ }^{*}$ Corresponding author
}

Keywords: Maker space, Ecosystem, Maker.

\begin{abstract}
Based on the ecosystem theory, this paper summarizes the meaning and characteristics of the maker space, and defines the ecosystem of the maker space, using three dimensions - - the customer ecosystem, the resource ecosystem and the maker spirit, and analyzes the marker space's three core mechanisms : entrepreneurial resource integration, "energy" transformation and ecosystem metabolism. Based on the meaning, structure, features, and operational mechanisms of the ecosystem of the maker space, three development paths are proposed, namely, enriching and optimizing the community of makers, accumulating high-quality entrepreneurial resources, and achieving seamless integration between creators and resources.
\end{abstract}

\section{Introduction}

On January 28, 2015, at the executive meeting of the State Council, the CPC Central Committee claimed its support for the development of the marker space to promote a wave of "mass entrepreneurship and innovation", and for the first time the maker space was written into the central document; subsequently, in the government work report at The Two Sessions, Premier Li Keqiang regarded public innovation as one of the two engines of China's economic development under the new normal, and the vigorous development of the maker space has thus begun.

At present, the theoretical research of the marker space has become more mature. Many scholars have conducted an in-depth analysis of the characteristics and structure of the marker space, and formed a unified view: the maker space shares many common characteristics with the ecosystem. However, the research of the operating mechanism of the maker space can still be deepened in academia. This article is based on this background, from the perspective of ecosystem theory, combining the current theoretical research results of the maker space, and exploring its future operating mechanism, just to improve the theoretical research results of the maker space.

\section{The structure of the ecosystem of the maker space}

The ecosystem of the maker space is mainly composed of maker ecosphere, resource ecosphere. The two parts are interlaced and interconnected, forming a complex but orderly entrepreneurial ecosystem.

\subsection{Maker ecosphere}

The maker ecosphere refers to the maker groups who enter the space. They are the fresh blood of entrepreneurial activities. The quantity and quality of makers will directly affect the future development of the maker space. Generally speaking, the number of makers is large, and their roles are diverse, including mainly college students, entrepreneurs, senior managers, returnees, scientists and technicians. In the promotion of double atmosphere, almost every maker possesses the most new technology or business model, and most of them have entrepreneurial talents. It is because these creative ideas and entrepreneurial talent are sowing in the maker space, thriving in resource 
ecosphere that ultimately the market was formed. Different from the traditional incubators and technology parks, makers in the public record space will closely and frequently exchange information with each other, they are keen to share their successful entrepreneurial experience, at the same time, in order to achieve complementary collaborator in entrepreneurial projects, they will actively cooperate with each other or sometimes become shareholders of a reciprocal company. It is this low centrality and high density maker ecosphere that promotes the material cycle, energy flow and information exchange of the ecosystem of the maker space.

\subsection{Resource ecosphere}

Resource ecosphere mainly includes two categories, one is entrepreneurial mentor mentors, venture investment organizations, accountants, lawyers, engineers and other professionals in the professional field, and industry chain related subject, these professionals provide management consulting, technical guidance, business operations and other technical knowledge to makers. For example entrepreneurial mentor will training on a regular basis to continually cultivate and enhance the makers' strategic entrepreneurial ability. In addition, the entrepreneurial platform of the maker space can also be used as one of the entrepreneurial resources. In general, the maker space are mostly set in the city buildings, coffee bar, garage and other places with convenient traffic, the platform can provide low cost stations and convenient service for makers, so that makers can make full use of their own entrepreneurial talent without being affected by the fixed work system constraints. Convenient entrepreneurial platform provides physical space for makers to carry out entrepreneurial activities, and professional and personalized service.is the necessary can met all makers' needs. Venture investment organizations also provide makers with rich and high-quality resources to promote the entrepreneurial projects for their growth.

\section{Set up the operating mechanism of the ecosystem of the maker space}

All elements in the maker space ecosystem fully realized their functions through efficient operating mechanism, which provided a good guarantee for the dynamic balance and efficient operation of the ecosystem. There are three main mechanisms of maker space: the integration mechanism of entrepreneurial resources, "Energy" transmission mechanism and the metabolic mechanism of the ecosystem. The three mechanisms interlaced and influenced each other, and joint together to promote the continuous development of the maker space.

\subsection{The integration mechanism of entrepreneurial resources}

The healthy growth of the entrepreneurial project needs "sunshine, air, water" and other nutrients. A start-up company needs all kinds of service institutions to provide resources for them, such as convenient platform from the maker space, policy support for government agencies, and strategic professional knowledge from entrepreneurial mentors and professionals. A successful project needs to get the funds from financial institutions, the makers may possess new technology and business model, but they lack excellent strategic vision and strategic knowledge; angel investors and venture capital institutions have broad strategic vision and insight of the market, and are eagerly searching for a good potential entrepreneurial projects. The high heterogeneity between the venture capital institutions and entrepreneurs increases the difficulty of integration, the maker space ecosystem provides a platform for exchange and combination of the two subjects. On this platform, close cooperation, mutual learning, mutual exchange, mutual trust and cooperation relationship between venture capital and entrepreneurs are fostered, the search and integration costs are greatly reduced.

\section{2 "Energy" transfer mechanism}

Similar to the natural ecosystem, the maker space ecosystem also has energy flow activities, and the stable operation and dynamic balance of the maker space ecosystem rely on energy and value transfer activities. A chain is formed by energy transmission between makers and all kinds of resources. There are close value exchange activities happen among all the subjects through the chain. Services institutions offer professional and business services to makers, venture capital 
institutions and angel investors support the market operation of the entrepreneurial projects and require a certain proportion of capital returns, makers provide labor services and support entrepreneurial activity. When the labor, capital and material resources are successfully injected into the entrepreneurial projects, if projects become a success, they will transfer the value of the product to the final consumer, investment institutions will get their returns, and all kinds of services has fulfilled its service value, energy conversion achieved success among all levels of the chain.

\subsection{Metabolic mechanism of the ecosystem}

The benign operation of the ecosystem of the maker space relies on the Survival of the fittest mechanism of the makers and resources. The first is the metabolic mechanism of the makers. As the main unit of entrepreneurial activity, although the maker space settles lower threshold, but not all of the entrepreneurial projects can successfully enter the space but those who meet the criteria. Other projects will be rejected; in the process of incubation, not all of the creative ideas will be transformed into entrepreneurial achievements, only those have the market value and meet consumer demand can be realized; an entrepreneurial project is "born" until it gets financial support from financial institutions. Through the heavy elimination mechanism, there are only some entrepreneurship projects with great quality in the space, which ensures the fresh and vitality of the space. In the aspect of resource metabolism mechanism, spatial operators will first set the entry threshold, and then evaluate and score service subject, only standard entrepreneurial resources can be assigned into the space and serve the makers; after entering the space, the same kind of service may need to compete for one promising entrepreneurial projects; when the resources subjects have settled in space for a period of time, they may need to face their performance appraisal conducted by the operators, and resources with poor efficiency will be eliminated. It is the three elimination mechanism that ensures the quantity and quality of space resources.

\section{Acknowledgement}

This research was financially supported by the National Undergraduate Innovative Training Program.

\section{References}

[1] S. Chen, L. Y. Xiang, R. J. Yu, The public record space of entrepreneurial ecosystem characteristics, structure, mechanism and Strategy -- Taking Hangzhou as an example, dream town business economics and management, vol. 11, pp. 35-43, 2015.

[2] T. M. Jia, L. H. Lei, M. N. Wang, Set up space ecosystem: connotation, characteristics, structure and operating mechanism, Science and Technology Management Research, vol. 11, pp. 8-14, 2017.

[3] Q. L. Zhuang, L. H. Lei, M. Y. Chen, Research on the PEST model based spatial ecosystem research, China Collective Economy, vol. 26, pp. 46-48, 2017.

[4] Y. P. Li, W. Chen, The current situation and prospect of Chinese public space research, China Science and Technology Forum, vol. 05, pp. 12-18+56, 2017.

[5] Q. Wang, Building a space entrepreneurship ecosystem for the construction of, Enterprise Economy, vol. 10, pp. 5-9, 2016.

[6] X. Hou, X. Jin, J. Wu, CAS from the perspective of public space characteristics and operational mechanism research, Information Magazine, vol. 10, pp. 195-200+119, 2016. 